\title{
¡EL ESTADO HA MUERTO. VIVA EL ESTADO!*
}

\section{THE STATE HAS DIED! A VIVA TO THE STATE!}

\author{
Augusto Trujillo Muñoz** \\ Fecha de recepción: 13 de enero de 2010 \\ Fecha de aceptación: 22 de febrero de 2010
}

* Este artículo hace parte de los trabajos desarrollados en el marco del doctorado en Ciencias Jurídicas de la Pontificia Universidad Javeriana.

** Doctorando en Ciencias Jurídicas de la Pontificia Universidad Javeriana de Bogotá, Magíster en Derecho de la Universidad Nacional de Colombia, especialista en Derecho Público de la Universidad Externado de Colombia. Posgrados en administración del Inalde de Bogotá y el Inap de Madrid. Director de la Revista de la Academia Colombiana de Jurisprudencia, tratadista en su especialidad y profesor universitario.

Correo electrónico: atm@cidan.net 


\section{RESUMEN}

Los estados nacionales nacieron de la paulatina disolución de la sociedad medieval y terminaron convertidos en un paradigma del pensamiento moderno. Sin embargo en el siglo xxi acusan factores de crisis. La nueva realidad "glocal" pone al descubierto muchas ficciones asumidas como verdades incontrovertibles durante los últimos quinientos años.

Palabras clave: Estado moderno, globalización, localismo, Estado y derecho.

Palabras clave descriptor: Nación, pensamiento político y social, filosofía de la globalización.

\section{ABSTRACT}

National states were born out of the gradual dissolution of the medieval society and ended up as a paradigm of the modern system of thought. Nonetheless in the $X X I$ Century there are crises factors present. The new "local" reality discovers many factions assumed as truths not subject to discussion during the last 500 years.

Keywords: modern state, globalization, localism, state and law, pluralism, democracy

Key word plus: National State, Political and Social Views, Globalization, Philosophy. 
Salvo en Europa, la Edad Media fue un período francamente luminoso. Durante ella los chinos, los hindúes, los árabes hicieron descubrimientos de importancia descomunal. Los hindúes encuentran el número cero, un concepto que revoluciona tanto las matemáticas como la filosofía; los chinos descubren la pólvora e inventan la brújula; los árabes el cálculo algebraico, los números arábigos y la alquimia. De esta última nació precisamente la química moderna.

Entre tanto, los pueblos más evolucionados de la América precolombina habían construido su propia civilización y algunos de ellos disfrutaban de una vasta red vial que sólo conoció Europa siglos después. Las vías de comunicación de los incas eran semejantes, en extensión y complejidad, a las construidas por los romanos durante el esplendor de su imperio. Pero además, algunas comunidades americanas conocían calendarios más exactos que los manejados por los europeos cuando llegaron al nuevo mundo y gozaban de una vida organizada en equilibrio pleno con la naturaleza.

Por el contrario, el Medioevo europeo - especialmente en Europa centralfue pobre en materia científica y discreto en materia filosófica. En su seno floreció una gran vocación por la guerra:

"Desde el siglo VI hasta el IX la situación de Europa no permitió mucha actividad filosófica o teórica y los bárbaros germanos no eran capaces de captar -no digamos nada de ampliar- los restos del saber antiguo que estaban a su disposición... Nuevas invasiones bárbaras producidas en los siglos X y XI -noruegos en el norte y hunos en el este- volvieron a amenazar con reducir a Europa a una situación de anarquía. Hasta la última parte del siglo XI cuando comenzó la gran controversia entre las autoridades espirituales y temporales, no volvió a haber un estudio activo de ideas políticas"1.

Los pueblos europeos, y en particular las tribus germanas, encontraron en la guerra su actividad cotidiana. Durante la Edad Media fueron ampliando paulatinamente su radio de influencia, pero mantuvieron su centro de gravedad en el norte de Alemania y luego en las orillas del Rin. Al amparo de sus príncipes guerreros surgió el feudalismo y se creó el sacro imperio romano-germánico.

La Europa latina registró un proceso de desarrollo diferente. Conservó su eje en las costas del sur, en donde se desarrollaron las ciudades y los municipios, el comercio y la navegación, el derecho gremial y el derecho local. La vida cotidiana funcionaba en medio de sociedades plurales. Lo demuestran los fueros hispanos y las ciudades italianas. En general, el ejercicio de las ideas -como en el resto de Europa- tuvo estímulo en conventos y abadías,

1 George H. Sabine. Historia de la teoría política. Pág. 170. Fondo de Cultura Económica, primera reimpresión colombiana. Bogotá. (1998). 
en la reflexión de eclesiásticos estudiosos y más tarde en las universidades, fundadas por órdenes religiosas o por clérigos de prestigio.

Sin embargo, tanto en la península itálica como en la península ibérica se consolidó un fenómeno de diversidad social, irrepetible en una Europa dominada por el sacro imperio. En ambas hubo guerras, pero en ninguna hubo feudalismo. Si lo hubo fue, en todo caso, un feudalismo atípico: la península itálica vio expandirse una cultura más bien urbana y la península ibérica una sociedad señorial, pero ninguna de las dos derivaba del régimen feudal ni funcionaba en torno a una estructura jerárquica.

Las ciudades-repúblicas de Italia recordaban los tiempos romanos y, algunas de ellas tenían origen etrusco. Habían sobrevivido tanto a la gloria como al ocaso del imperio y mantenido el diseño republicano que tuvieron en la vieja Roma. Los fueros locales de España surgieron a medida que se desarrollaron comunidades de aldea y se fortalecieron expresiones jurídicas diversas surgidas en torno al derecho romano, al derecho consuetudinario, al derecho canónico e incluso al derecho musulmán.

Al contrario de ciertas creencias propiciadas por la modernidad, España fue siempre pobre en jerarquías ${ }^{2}$. A pesar del alto contenido religioso tanto de sus comunidades como de su entramado institucional, los pueblos hispanos se formaron en medio del respeto a la diversidad y de la convivencia de culturas local/regionales, cada una de ellas con instituciones propias, autonomía política y capacidad para crear derecho. Las Cartas Pueblas otorgaron concesiones a grupos de súbditos dispuestos a repoblar o a recuperar tierras que les habían sido arrebatadas por los moros. Al restablecerse en ellas consagraban su propio régimen jurídico. Así surgieron las primeras formas de derecho local que luego se consolidaron en los fueros territoriales.

"Los siglos XI y XII son considerados como el momento de plenitud de los ordenamientos forales. Durante este período los fueros no son ordenamientos estáticos sino que, por el contrario, son el más fiel exponente del carácter dinámico del derecho"’3. No sin razón, en esa época, la península se llenó de consejos municipales y la Curia Regia de las monarquías hispanas se abrió a delegaciones de los municipios, inaugurando un sistema de representación que, luego, fue característica propia de los parlamentos modernos.

Este hecho ocurrió por primera vez en el año 1188 en el reino de León y en él se encuentra el origen de las Cortes, nombre dado al actual parlamento español. Pero además ocurrió casi tres décadas antes de que, en 1215, los

2 Es muy significativa la fórmula utilizada durante la Edad Media en las Cortes de Aragón, para elegir y ofrecer vasallaje al rey: "Nosotros que, solos, somos iguales a vos, pero que juntos somos más que vos, juramos a Vuestra Excelencia, que no sois mejor que nosotros, aceptaros como rey, con tal de que respetéis nuestras libertades y leyes, pero no de otra manera". En medio de la realidad multicultural peninsular, no resultaba claro si el rey otorgaba graciosamente los fueros a la comunidad, o ésta se los imponía al monarca.

3 José Sánchez-Arcilla Bernal. Historia del derecho español. Op. cit. Pág. 149. Cálama. Barcelona. (2005) 
ingleses produjeran su célebre Carta Magna, un documento típicamente medieval que, sin embargo, los ingleses asumen como el origen de la institución parlamentaria moderna. A diferencia de otros pueblos de Europa, en España las instituciones siempre fueron más que el rey, inclusive en los tiempos del absolutismo regio ${ }^{4}$.

Este fenómeno hunde su raíz en el viejo constitucionalismo medieval cuyo sentido fue, precisamente, el de limitar el poder. Pensadores de esos tiempos como Juan de Salisbury, Nicolás de Cusa, Francisco de Vitoria, entre otros, consideraron siempre que la ley es obligatoria tanto para el rey como para el súbdito. La idea de la soberanía tanto del monarca como del Estado se corresponde con una concepción plenamente moderna.

Desde el siglo VII Isidoro DE SEvilla diferenció entre lex y constitutio, entendiendo por la primera una decisión con participación de la comunidad y por la segunda, una decisión unilateral del monarca. Pero quizá fue JUAN DE MARIANA, dentro de un criterio que privilegió siempre la autoridad del derecho sobre la del gobernante, quien sistematizó toda una concepción en torno a la línea doctrinaria del constitucionalismo medieval. Así lo expresa SABINE:

"Como Hotman, admiraba las instituciones medievales, en especial las representadas por las Cortes de Aragón. Consideraba a las Cortes como guardianes de las leyes del país a las que el monarca está plenamente sujeto. Hacía derivar el poder del monarca de un contrato con el pueblo, representado por las Cortes, a las que está reservado el poder de modificar el derecho. De ahí que pueda eliminarse al rey en caso de que viole la norma fundamental.

La característica más importante de la teoría de Vniversitas fue la de considerar el origen y evolución del gobierno como un proceso natural que se produce bajo el impulso de necesidades humanas, y en estos cimientos basaba la afirmación de que una comunidad tiene que poder controlar o poder deponer siempre a los gobernantes que han sido creados por su necesidad. Vniversitas se aproxima mucho más que el autor de vindictae contra tyrannos a una concepción no teológica de la sociedad civil y de sus funciones"s.

Hacia el año 630 Isidoro de Sevilla había recogido una serie de cánones pontificios en una colección que se conoció como la Hispana. Los visigodos mantuvieron las instituciones romanas para gobernar con ellas las relaciones de la población vernácula, pero trajeron su derecho consuetudinario para aplicarlo a la población visigoda. Veinticinco años más tarde el rey visigodo Recesvinto promulgó el Forum o Liber Iudiciorum, conocido históricamente como el origen del Fuero Juzgo, una legislación con propósitos unificadores que, sin embargo, encontró obstáculos en la diversidad cultural de la

4 Sería probable que ningún rey español se hubiera atrevido a pronunciar la famosa frase de Luis XIV: "El Estado soy yo".

5 George H Sabine. Op. cit. Pág. 306. 
península y, más tarde, en las nuevas expresiones jurídicas originadas en la invasión musulmana.

Paulatinamente los visigodos se fueron romanizando, pero mantuvieron su derecho consuetudinario al lado de las nuevas leyes escritas. Mientras tanto se produjo una actividad conciliar tan intensa que fue necesario compilar las normas canónicas. En esa forma se abrió paso una especie de pluralismo jurídico que, de alguna manera, terminó convirtiéndose en característica propia de la diversidad ibérica y en una constante del derecho español a lo largo de su historia.

Todas aquellas expresiones plurales recibieron fuerte golpe con el advenimiento de la edad moderna. Las monarquías desplazaron a las poliarquías, la idea de Estado desplazó a la de comunidad, la de soberanía desplazó a la de autonomía, la del monismo jurídico desplazó a la de los pluralismos. En su vocación universal y uniformista, el pensamiento moderno pretendió eliminar toda idea autonómica e identificó Estado con derecho. La realidad institucional del Estado-nación monopolizó la producción de normas jurídicas y terminó convirtiéndose en uno de los paradigmas fundamentales de la modernidad.

Con los antecedentes señalados España se convierte en la potencia más importante del mundo. Conformó su Estado en torno a unos monarcas que unificaron políticamente la península, pero haciendo uso de unos materiales propios de su tránsito específico por una específica ruta histórica. A pesar de la preeminencia de la religión católica, la península ibérica fue testigo de una curiosa integración entre los pueblos visigodos, la población hispanorromana, los judíos y el islam. Cuando Toledo fue la capital del reino, sus habitantes vivían en medio de una convivencia no sólo intercultural sino interreligiosa. Desde entonces España es un escenario de diversidades cuya vigencia llega hasta los tiempos actuales.

Italia también es producto de influencias diversas, pero sólo logró su unidad política hacia 1870 , conformando su estado a partir de regiones históricas con evolución propia. "Los municipios y las regiones son la vida,

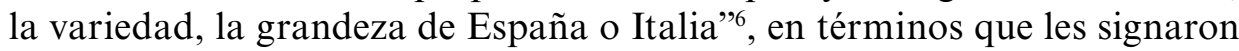
una evolución distinta a la del resto de Europa. El ascenso al trono español de la Casa de Trastámara con los Reyes Católicos no sólo significó la unidad política de la península ibérica, sino la incorporación de la península itálica al dominio de los monarcas hispanos.

6 Juan Ferrando Badía. Estudios de ciencia política. Tecnos. Madrid. (1992). 


\section{La concepción estatalista}

El primer pensador que emplea la palabra stato, en sentido moderno, es NicoLÁs MaQuiavelo, una especie de filósofo de la acción, que sueña con la unidad italiana. Formula en El príncipe una visión del Estado pensando en Lorenzo de Médicis el príncipe mecenas de Florencia, y en el rey español Fernando de Aragón, quien también era rey de Nápoles. Maquiavelo se convierte en uno de los primeros pensadores modernos y en inspirador de una expresión institucional que Italia sólo pudo ver trescientos años después.

España pretendió ingresar a la modernidad sustentada en su propia experiencia histórica. El absolutismo de los Reyes Católicos creó el Estado nacional español, pero sus pensadores se apartaron tanto como pudieron de los profetas burgueses que anunciaban el advenimiento de la felicidad unido a las virtudes del protestantismo, del capitalismo y del liberalismo. El renacimiento significó el auge de Europa y la ulterior proyección de un pensamiento que impuso una visión eurocéntrica del mundo. La revolución era protestante y burguesa, mientras que la tradición era medieval y católica.

En otras palabras, España perdió la guerra de las ideas que conformaron el pensamiento moderno. Mantuvo las bases de su cultura y proyectó sobre sus colonias de América muchas influencias. "La huella del pensamiento español permanece en algunas de nuestras actuales instituciones y la impronta de la democracia local da testimonio de que hemos debido detenernos más a pensar nuestros países, antes de comprar la mercancía ideológica norteamericana, británica y francesa" . Pero hacia el siglo XVII se comenzó a producir el desplazamiento del eje de lo hispano al eje de lo anglosajón.

La doctrina del contrato social "que se inicia en SuÁrez y Althusio, continuará luego en nombres tan significativos como Grocio, PUfFENdorf, HobBes, LocKe, hasta llegar a su práctica disolución en el pensamiento de un KANT que se debate entre la herencia de un contractualismo individualista y un republicanismo humanista... esta doctrina significa un correlato teórico de unos supuestos reales que en el mundo histórico se corresponden con la afirmación del Estado"8.

La sola idea de Estado supuso una revolución gigantesca en el pensamiento político. Amasada en el ámbito renacentista encontró justificación en los primeros pensadores modernos. También la idea de revolución es propia de la modernidad. Desde principios del siglo XIX hasta finales del siglo XX las conquistas de las tres grandes revoluciones liberales -la inglesa, la norteame-

7 Augusto Trujillo Muñoz. El Estado y el derecho. Pág. 89. Academia Colombiana de Jurisprudencia. Bogotá. (2001).

8 Eloy García. El último triunfo de la libertad: la democracia constitucional ante su momento maquiavélico. Pág. 35. Universidad Externado de Colombia. Bogotá. (2000). 
ricana y la francesa- constituyeron los insumos fundamentales de la ciencia política y del derecho público.

"La modernidad como proyecto racional emancipatorio supuso que si los principios y las valoraciones descansaban en la razón, todos los hombres por igual debían comprenderlos y compartirlos. Por eso cada propuesta nueva, desde el idealismo kantiano hasta el materialismo marxista, tuvo una vocación universal. En esa vocación se fueron perdiendo los matices, de manera que las religiones, las etnias, los gentilicios, cedieron el lugar a formas identificatorias de carácter racional.

Así se construyeron los paradigmas de la modernidad. El hombre se situó en el centro del universo, la burguesía en el centro de la sociedad y el Estado-nación en el centro de la ciencia política. Las nuevas potencias expandieron su influencia por el mundo, mientras ampliaban mercados y proyectaban un pensamiento sustentado más en intereses que en valores" .

Algo similar ocurrió con la revolución socialista. El marxismo-leninismo fue otro producto del pensamiento moderno. Asumió el concepto de Estado, un poco a la manera de HoBbes, sobre la base de que el "hombre es un lobo para el hombre" y se comprometió con el proyecto de una sociedad universal, cuyo elemento central no sería ya la burguesía sino el proletariado.

La neutralidad universal del liberalismo y el compromiso universal del socialismo los distanció a ambos de una realidad que - por cuenta del pluralismo político-evolucionaba inevitablemente hacia el reconocimiento de matices en el seno de la sociedad. Uno y otro resultaron incapaces de dar cuenta del hecho de la pluralidad. Ambos, en nombre de la igualdad, desconocieron valores fundamentales: aquél las diferencias y éste las libertades.

BobBIo fue uno de los primeros juristas que puso de presente el fenómeno, al definir la teoría estatalista del derecho como producto de la formación de los Estados nacionales, que surgieron de la paulatina disolución de la sociedad medieval:

"Esta sociedad fue una sociedad pluralista, es decir, formada por varios ordenamientos jurídicos, que se oponían o que se integraban: por encima de lo que hoy son los estados nacionales había ordenamientos jurídicos universales como la Iglesia y el Imperio, y había ordenamientos particulares por debajo de la sociedad nacional, como los feudos, las corporaciones y los municipios... El Estado moderno se fue formando a través de la eliminación y la absorción de los ordenamientos jurídicos superiores e inferiores por la sociedad nacional... La tendencia a identificar el derecho con el derecho estatal, que hoy todavía existe,

9 Augusto Trujillo Muñoz. Democracia y territorio: el ordenamiento territorial entre el derecho y la politica. Pág. 120. Siglo del Hombre Editores. Bogotá. (2007). 
es la consecuencia histórica del proceso de concentración del poder normativo y coactivo que caracterizó el surgimiento del Estado nacional moderno"10.

Como producto típico de la modernidad el Estado-nación fue pensado primero y exportado luego por Europa al resto del mundo, en un proceso que fracturó el ritmo social de los pueblos de América y lesionó sus potencialidades culturales y políticas. Los marcó con la impronta de una dependencia espiritual y económica que los obligó a crecer con el centro de gravedad situado afuera. Tal vez nadie, excepto Bolívar, fue consciente del alcance de esos acontecimientos.

El compromiso del Libertador con la Gran Colombia, su idea del Congreso Anfictiónico de Panamá, su propuesta de la Constitución Boliviana, forman parte de una inmensa preocupación suya por construir instituciones legítimas, es decir, con respaldo en el contexto histórico-social, con respeto por la identidad, incluso con capacidad para reconocer factores de autonomía en los pueblos liberados.

Bolívar tenía claro que no hablaba para la América india ni para la Europa blanca, sino para pueblos nuevos, con mayor o menor influencia de su pasado -aborigen o ibérico-pero con una entidad sociocultural distinta de aquellas dos fuentes y diversa en sus propias realidades sociales. El Estado en los países iberoamericanos, desde su propio origen, fue débil y artificial. No obstante ello, nadie osaba discutir sus limitaciones. Si había problemas en las nuevas repúblicas la responsabilidad no era del Estado sino de sus habitantes, supuestamente mal formados para la ciudadanía.

Semejante diagnóstico no desaparece con el advenimiento del socialismo. También éste necesitaba fortalecer el Estado para convertirlo en militante de unos objetivos de clase. No obstante, la nueva ideología naufragó en medio de una realidad que -a contrapelo del pensamiento moderno-cada día afirmaba más la naturaleza plural de las sociedades contemporáneas. En la segunda mitad del siglo XX emerge la idea de posmodernidad, un concepto que, no por ambiguo, dejó de aportar una nueva actitud y unos nuevos códigos para leer unas nuevas realidades ciertamente desatendidas por la modernidad.

La Unión Europea es el mejor ejemplo de un traslado de soberanía nacional hacia una nueva forma institucional en construcción, aceptado voluntariamente por los Estados nacionales. Son conscientes de que acusan factores de crisis. Ceden potestades hacia el ámbito supranacional a cambio de supervivencia y competencias hacia el ámbito subnacional por legitimidad. Lo nacional pierde sentido entre una globalización inevitable por razones económicas o tecnológicas, y un localismo indispensable para mantener al alcance ciudadano los procesos democráticos. Es la realidad apabullante de

10 Norberto Bobbio. Teoría general del derecho. Pág. 9. Temis. Bogotá. (1987). 
un mundo glocal, pero el Estado insiste en afirmarse como actor estratégico de ambos procesos. ¡El Estado ha muerto. Viva el Estado!

\section{Repensar instituciones}

De alguna manera el mencionado proceso europeo, dirigido a construir una nueva institucionalidad en el viejo continente, es el resultado de la necesidad que los europeos han visto de "repensar a Europa". La idea no es, probablemente, "disolver ni sustituir a la nación, sino volver a interpretar su concepto a la luz... de una nueva concepción del cosmopolitismo político". A partir de tal idea surgen unos interrogantes:

“Cómo puede vislumbrarse y fundarse, más allá de los viejos estabilizadores, una nueva forma de sociedad y de política; cómo puede ésta afianzarse dentro y fuera tomando como base las formas históricamente determinadas de nacionalidad, pero a la vez, abriéndolas y ampliándolas?

¿Cómo es posible una integración social y política a través de la cosmopolitización?

¿Hasta qué punto es posible abrir el horizonte para esta realidad desligando las ideas y los conceptos fundamentales de lo social y lo político (sociedad, Estado, política, desigualdad social, movilidad, etnicidad, justicia, solidaridad, etc.) de la ortodoxia nacional y redefiniéndolos desde un punto de vista cosmopolita? ${ }^{11}$.

Trabajando sobre categorías europeas, BECK y GRANDE se atreven a afirmar que una "Europa cosmopolita" es la última utopía realmente en marcha en el viejo continente y se aventuran a explorar en una dirección que supone la construcción de expresiones institucionales fundadas en el reconocimiento cultural del otro. Este planteamiento supone revisiones al pensamiento moderno.

Con mayor razón en el nuevo mundo -debido al origen artificial de su estado- es necesario repensar instituciones a partir de lo que significan su propia historia, sus propias culturas y su propio contexto. Para ser inteligible la idea de Estado-nación necesita de la modernidad. Pero cuando se revisan los supuestos universalistas y se examinan las formas comunales de organización que se han pretendido rescatar en los últimos años, surge un nuevo y profundo debate del cual tendrá que ocuparse en forma prioritaria el siglo XXI.

El paradigma moderno no sólo identificó Estado con nación, sino también Estado con derecho. Éste se fundamenta en aquél y aquél en éste, dentro de una especie de correa transmisora de doble vía, en la cual los dos conceptos -Estado y derecho- construyen mutuamente su propia legitimidad. Para el liberalismo político la legitimidad se desprende del ejercicio del poder político

11 Ulrich Beck \& Édgar Grande. La Europa cosmopolita. Pág. 22. Paidós. Barcelona. (2006). 
"en concordancia con una Constitución, cuyos principios esenciales todos los ciudadanos libres e iguales pueden razonablemente suscribir a la luz de principios e ideales aceptables para su razón humana común"’2.

Pero a la luz de la historia del derecho habría que decir que la legitimidad tiene un origen de facto que hace del Estado la única fuente de poder legítimo. Los párrafos siguientes son reveladores:

"El Estado, en cuanto expresión del proceso de racionalización en que consiste la modernidad, manifiesta la lógica propia del poder. Racionalidad, poder, Estado, son aspectos de un mismo proceso de formalización instrumental. Sacar al Estado de la órbita normativa para incluirlo en la del poder, supone ya no sólo reconocer al Estado moderno tal como ha quedado individualizado históricamente, sino también hacer patente la identidad de poder y razón, que constituye el callejón sin salida de la modernidad...

El Estado es una creación original de la modernidad europea, ¿cabe entonces trasplantarlo sin más a América Latina? Pero ocurre que también América es una creación de la Europa moderna. América, la anglosajona y la latina, se constituyen en un proceso de europeización que se inicia justamente cuando empieza la modernidad...

... Aquí está el nudo del problema: Iberoamérica surge con la modernidad, recogiendo muchos de sus elementos, pero también asimilando otros que le preceden o que son autóctonos o provienen de otras culturas. El europeísmo acérrimo de las clases dirigentes latinoamericanas no puede hacernos olvidar los aportes de las culturas indígenas y africanas. El resultado es un producto nuevo, original, que no encaja en las coordenadas europeas, ni en las medievales... ni en las capitalistas, aunque éstas hayan terminado por ser las dominantes. No es extraño que desde que América Latina toma conciencia de sí, le haya atormentado la pregunta por su propia identidad...

La paradoja que define hoy la cuestión del Estado europeo parece que se reproduce en el latinoamericano: el actual Estado nacional, por inacabado que se presente, resulta ya inservible para resolver los problemas económicos, sociales y políticos planteados; la integración latinoamericana, incluso a escala regional, pese a no pocas buenas intenciones y numerosos intentos, no parece demasiado factible. América Latina precisa de una integración supraestatal para resolver sus problemas, pero ésta cada día parece menos probable"13.

Los apartes transcritos sintetizan los problemas que afectan a una institución específica, pensada por la modernidad, dentro de un contexto específico, pero convertida por sí misma en solución definitiva tanto en el espacio como

12 John Rawls. Liberalismo político. Pág. 140. Fondo de Cultura Económica, primera reimpresión en Colombia. Bogotá. (1996).

13 Ignacio Sotelo. "El Estado moderno". En Filosofía política II, Teoría del Estado. Pág. 41. Edición de Elías Díaz y Alfonso Ruiz Miguel. Editorial Trotta. Madrid. (1996). 
en el tiempo ${ }^{14}$. Sin embargo, esta nueva realidad glocal perfilada en el tráfago empírico y teórico de los últimos años puso al descubierto muchas ficciones asumidas como verdades incontrovertibles desde hace quinientos años.

El Estado moderno es excluyente: a partir de la ficción de que los grupos sociales diferentes estaban situados fuera de su organización institucional, no previó que, en un momento dado, pudieran incluirse dentro de ella. Esa constatación implica la puesta en marcha "de una cierta diferenciación o fragmentación del concepto tradicional de ciudadanía, por cuanto los grupos diferenciados reclaman también sus derechos y libertades desde un punto de vista jurídico, a la vez que el reconocimiento y preservación de su propia identidad desde un punto de vista político"15.

"Esto quiere decir que la protección jurídica, política y social -estructurada en los diversos tipos de derechos fundamentales- derivada del estatus jurídico de la 'ciudadanía' ya no responde hoy día a un proceso unilateral entre la soberanía del Estado y el ciudadano de tal Estado, sino que deriva de una interrelación conflictiva entre múltiples y diferentes esferas jurídico-políticas tanto internas (las propias, y cada vez más descentralizadas, de cada uno de los Estados) como externas (las derivadas de las múltiples instancias transnacionales). La consolidación de estas múltiples esferas jurídico-políticas quiebra la concepción tradicional del Estado moderno estructurado como Estado-nación"16.

Pero también se desdibujaron otras ficciones como el carácter absoluto del Estado y la clásica noción de soberanía. En efecto, aquel dio paso al Estado democrático y ésta se ha debilitado con la construcción de instituciones supranacionales y transnacionales. La evolución de la teoría de la democracia descubrió igualmente una falacia en la concepción lineal de la historia que depositaba la posibilidad de grandes impulsos sociales en la idea de revolución. Ahora ésta implica una actitud desfavorable para la democracia porque supone una homogeneidad social inexistente, que lleva a considerar traidor al adversario, señala TouRAINE ${ }^{17}$. Si el activista no es simpatizante de unas tesis, sino un cruzado de su ideología, la política deja de servir para el diálogo y sólo quedan espacios para la confrontación. Así es imposible cualquier posibilidad de convivencia.

Pero además, como lo recuerda SANTOS, las posibilidades emancipatorias inherentes al pensamiento moderno se redujeron casi hasta su neutralización

14 Desde Bodino se asumió que la soberanía es el poder que se constituye, en forma perpetua, a favor del Estado. Y desde HobBes ese estado se concibió como algo absoluto: el Leviatán, cuyo sentido es controlar la violencia y el abuso de los hombres en su estado de naturaleza.

15 María José Fariñas Dulce. "Ciudadanía universal versus ciudadanía fragmentada" en El vínculo social: ciudadanía y cosmopolitismo. AA. VV. Pág. 173. Tirant lo Blanch. Valencia. (2002).

16 María José Fariñas Dulce. Op. cit. Pág. 179.

17 Alain Touraine. Crítica de la modernidad. Pág. 421. Temas de hoy. Madrid. (1993). 
en el momento en que la trayectoria de la modernidad se enredó en el desarrollo del capitalismo. "Al no ser cumplidas, las promesas de la modernidad se transformaron en problemas para cuya solución los paradigmas modernos resultaron insuficientes".

Sin proponérselo, el Estado nacional comenzó a deshacerse de la misma forma como se hizo. O más bien, al revés de como se hizo: en lugar de absorber los ordenamientos jurídicos superiores e inferiores, decidió resignar competencias a su favor. Por esa vía, y también sin proponérselo, el Estado abrió la puerta para un tránsito del pluralismo jurídico y social hacia el pluralismo jurídico. SANTos lo expresa así:

"Parto de la verificación... de que, al contrario de lo que pretende la filosofía política liberal y la ciencia del derecho que sobre ella se construyó, circulan en la sociedad no una sino varias formas de derecho o modos de juridicidad. El derecho oficial, estatal, que está en los códigos y es legislado por el gobierno o por el parlamento, es apenas una de esas formas, aunque, tendencialmente, la más importante... Parto, así, de la idea de pluralidad de los órdenes jurídicos o, de forma más sintética y corriente, del pluralismo jurídico"18.

En el Medioevo y aún en el renacimiento el pluralismo jurídico fue producto de una organización social basada en la autonomía de unas comunidades frente a otras. Las poliarquías medievales no eran resultado del desorden sino de la diversidad. De una diversidad que ha vuelto a hacerse evidente en la medida en que las sociedades se hacen más complejas y que tiene que ver con los derechos de las minorías, es decir, con "el reconocimiento de su derecho colectivo en un Estado que antes no reconocía sino los derechos individuales y cuyo proyecto histórico de siglos fue la unificación legal, política y cultural"19.

En efecto, existen minorías culturales cuyo referente fundamental no es el individuo sino la comunidad. En esos casos no funciona la concepción de unos derechos humanos estructurados en torno a individuos. Para muchas minorías culturales "el concepto mismo de derechos humanos es desconocido o se encuentra en conflicto fundamental con su visión del mundo: una visión en la cual la persona no es tan importante como la comunidad y en donde los seres humanos no son el centro sino solamente una parte del universo" ${ }^{20}$. El pensamiento moderno suele desconocer esa problemática. Por lo mismo, cualquier respuesta del Estado moderno resulta inadecuada para tales situaciones.

18 Boaventura de Sousa Santos. Crítica de la razón indolente. Pág. 232. Desclée. Bilbao. (2003).

19 Fernando Vizcaíno. "Estado multinacional y globalización". En Nación y nacionalismo en América Latina. Jorge Enrique GonzÁlez (editor). Pág. 34. Clacso y Universidad Nacional de Colombia. (2007).

20 Daniel Bonilla Maldonado. La Constitución multicultural. Pág. 22. Universidad de los Andes, Pontificia Universidad Javeriana. Siglo del Hombre Editores. Bogotá. (2006). 
Probablemente, nuestra América deberá construir categorías nuevas y propias. En todo caso su organización institucional no puede seguir pensando en forma homogénea sociedades que no lo son, pues eso conspira contra la seriedad de una reflexión que debe comprometerse con el diseño de nuevas reglas de juego. Colombia se ha negado a reconocerse en sí misma, en su propio territorio, en su compleja sociología, en la riqueza de su historia, en la multiplicidad de su cultura. Las posiciones neoliberales y neomarxistas -que a menudo son las mismas del pasado-alimentan con una lógica propia de la guerra fría los extremos de una confrontación armada que niega la crisis del Estado-nación y desconoce la necesidad de refundar instituciones.

En la formación del pensamiento no hay recetas. Es necesario diseñar unas reglas de juego capaces de manejar unas patrias que no son nacionales y que, de seguro, nunca lo fueron. A menudo sus problemas tienen que ver más con soluciones extranacionales e incluso con respuestas que exigen más presencia de sociedad civil que de organización política. En el mundo actual existen comunidades sometidas a la persecución o al abandono, cuya tragedia apenas se conoce en el mundo, simplemente porque es ignorada por la comunidad internacional. Muchos problemas del Magreb árabe, del mundo kurdo, de las minorías chinas, de las comunidades indígenas americanas no han sido resueltos - a veces ni siquiera abordados-por los organismos internacionales simplemente porque no figuran en la agenda de ningún Estado-nación.

Todo eso exige un tratamiento que desborda la dimensión del Estado nacional; que exige asociar realidad histórica y social con diseño institucional; que demanda la acción de revisar la estructura de un Estado nacional delicuescente que, tal vez por lo mismo, no ha podido construir una democracia sin déficits y una ciudadanía con responsabilidad. Es preciso explorar en ese complejo escenario, haciendo énfasis en el contexto de América ibérica, cuyo gran desafío en el siglo XXI es encontrarse a sí misma. 


\section{BIBLIOGRAFÍA}

Ulrich Beck \& Édgar Grande. La Europa cosmopolita. Pág. 22. Paidós. Barcelona. (2006).

Norberto Bobbio. Teoría general del derecho. Pág. 9. Temis. Bogotá. (1987).

Daniel Bonilla Maldonado. La Constitución multicultural. Pág. 22. Universidad de los Andes, Pontificia Universidad Javeriana. Siglo del Hombre Editores. Bogotá. (2006).

Boaventura De Sousa Santos. Crítica de la razón indolente. Pág. 232. Desclée. Bilbao. (2003).

María José Fariñas Dulce. Ciudadanía universal versus ciudadanía fragmentada. En El vínculo social: ciudadanía y cosmopolitismo. AA.VV. Pág. 173. Tirant lo Blanch. Valencia. (2002).

Juan Ferrando Badía. El estado federal, el unitario y el estado autonómico. TeCnos, Madrid, 1986.

. Estudios de ciencia política, TeCnOs, MADRID 1992.

Eloy García. El último triunfo de la libertad: la democracia constitucional ante su momento maquiavélico. Pág. 35. Universidad Externado de Colombia. Bogotá. (2000).

John Rawls. Liberalismo político. Pág. 140. Fondo de Cultura Económica, primera reimpresión en Colombia. Bogotá. (1996).

George H. Sabine. Historia de la teoría política. Pág. 170. Fondo de Cultura Económica, primera reimpresión colombiana. Bogotá. (1998).

José Sánchez-Arcilla Bernal. Historia del derecho español. Op. cit. Pág. 149. Cálama. Barcelona. (2005).

Ignacio Sotelo. El Estado moderno. En Filosofía política II, Teoría del Estado. Edición de Elías Díaz y Alfonso Ruiz Miguel, Pág. 41. Editorial Trotta. Madrid. (1996).

Alain Touraine. Crítica de la modernidad. Pág. 421. Temas de hoy. Madrid. (1993).

Augusto Trujillo Muñoz. Democracia y territorio: el ordenamiento territorial entre el derecho y la politica. Pág. 120. Siglo del Hombre Editores. Bogotá. (2007). Bogotá. (2001).

El Estado y el derecho. Pág. 89. Academia Colombiana de Jurisprudencia.

Fernando Vizcaíno. Estado multinacional y globalización. En Nación y nacionalismo en América Latina. Jorge Enrique GonzÁlez editor, Pág. 34. Clacso y Universidad Nacional de Colombia. (2007). 